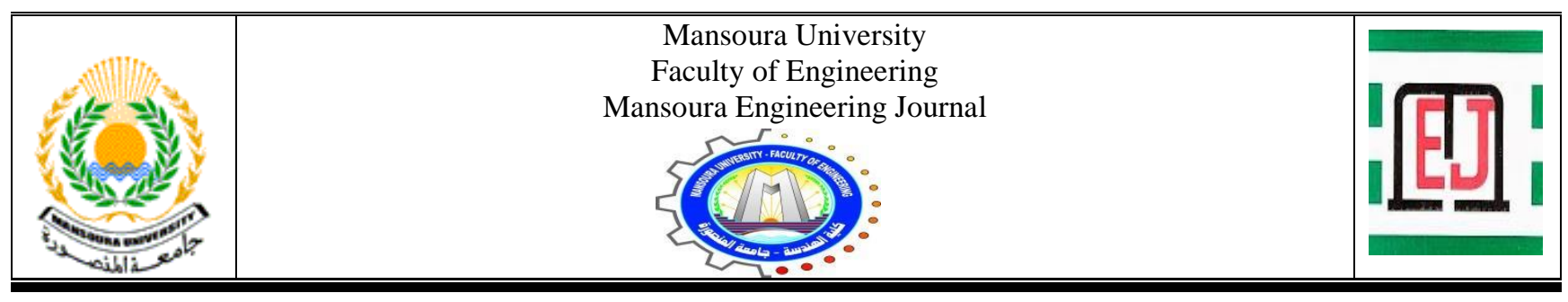

\title{
Optimum Topology of Power Distribution Networks Using Sunflower Optimizer for Loss Reduction
}

\author{
Hany S. E. Mansour, Basem E. Elnaghi, M. N. Abd-Alwahab and M. M. Ismail
}

\begin{tabular}{|l|}
\hline KEYWORDS: \\
Network \\
reconfiguration, power \\
loss, sunflower \\
optimizer, graph theory, \\
optimization
\end{tabular}

Abstract- The network reconfiguration can aid in loss reduction in distribution systems. A neoteric optimization method, Sunflower Optimizer (SFO), is suggested for addressing the reconfiguration of power distribution networks case. The main problem is to determine the network's optimal topology, which satisfies the objective function by considering the problem constraints. The fitness function is formulated to achieve the maximum percentage of active power loss decrease. To obtain the load flow solution, an efficient approach is applied called Backward/forward sweep. Besides, an improved graph theory is developed to address the configuration variations problem. The suggested optimization approach is executed on three power distribution networks: IEEE 33, 69, and 119 bus networks. The efficiency of the suggested SFO is verified by evaluating its operational characteristics. The obtained test results show that the percentage of active power loss reduction is maximized to $31 \%, 56 \%$, and $33 \%$ for the IEEE 33, 69, and 119 bus networks, respectively. Finally, the introduced SFO approach's superiority is also confirmed by measuring its outcomes with other approaches..

\section{INTRODUCTION}

A $S$ of late, the demand for electric energy for industries and households has grown substantially. This growth leads to environmental and economic problems. Also, nearly 70 percent of the overall loss is wasted in power distribution networks [1]. This power

Received: (06 Feburary, 2021) - Revised: (30 March, 2021) - Accepted: (01 Aapril, 2021)

Corresponding Author: Hany S. E. Mansour, Assistant lecturer at Electrical Engineering Department, Faculty of Engineering, Suez Canal University, Ismailia, Egypt (hany_salem@eng.suez.edu.eg Tel:0020-102-4327200)

Basem E. Elnaghi, Associate Professor at Electrical Engineering Department, Faculty of Engineering, Suez Canal University, Ismailia, Egypt.

M. N. Abd-Alwahab, Head of Electrical Engineering Department, Faculty of Engineering, Suez Canal University, Ismailia, Egypt.

M. M. Ismail Professor at Electrical Engineering Department, Faculty of Engineering, Helwan University, Helwan, Egypt. appears in the form of dissipated heat energy that increases the associated network elements' temperature and can lead to insulation failure. Besides, failure statistics revealed that distribution networks have a significant portion of the interruption of supply to the users (90\%) [2]. Therefore, minimizing real power loss in power distribution networks is a vital topic in power network research. So, many ways are suggested to obtain minimal power loss such as network reconfiguration, capacitor banks placement [3], [4], distributed generators integration [5], and load balancing. The present research deals with the network reconfiguration technique.

Reconfiguration of power distribution networks means changing the topology of the network by modulation the status of tie and sectionalizing switches with maintaining the network radiality.

Different approaches have been submitted to address the issue of distribution network reconfiguration in literature. A literature review study documenting the different optimization techniques for network reconfiguration can be found in Ref. [6]. Artificial intelligence and heuristic optimization 
approaches have been implemented by various researchers to address the reconfiguration of the power distribution networks problem. In [7], the authors have discussed the issue of network reconfiguration, considering the power loss minimization. Besides, Baran and $\mathrm{Wu}$ have completed the work of [7] and presented a load balancing indicator as well losses decrease [8]. In [9], the switch exchange technique has been proposed to reconfigure the system topology. It looks for adequate solutions to minimize losses by using minimal treesearch. The results revealed that the implemented algorithm accomplished the optimum or near-optimal reconfiguration of the network.

A heuristic approach also has been introduced to achieve minimal distribution network losses [10]. At first, the radial configuration has been converted to mesh. Then, an optimal pattern of load flow has been developed. Finally, the branch that carried the minimum current has been removed. This approach is a greedy technique that cannot certainly warranty the viability of the obtained solution. Gomes et al. [11] have also suggested the heuristic approach, which initiates with a meshed network got by closing all tie switches. Thereafter, to remove these loops, the switches are unlocked sequentially. The opening state depends on the computation, using a power flow program, of the lower total network losses.

Besides, Das has formulated a heuristic approach for distribution network reconfiguration in view of multiobjectives in a fuzzy frame. The problem's aims have comprised the total real power loss minimization, load balancing, current limit infraction, and voltage deviation reduction [12]. Further, Zhu has suggested the refined genetic algorithm to address the topology reconfiguration problem. The principal objective has been presented to decrease the active power loss in distribution networks. The presented approach has applied a contest technique to improve the traditional crossover and mutation pattern, to avoid the early convergence [13].

Nara et al. [11] have presented the genetic algorithm to resolve the topology reconfiguration problem for the first time. The objective function has been designed to achieve minimum power loss. The genetic algorithm has also been applied to address the topology reconfiguration issue in [14-16]. Besides, there have been significant articles that solved the distribution network reconfiguration dilemma by applying other meta-heuristics methods such as plant growth [17], particle swarm technique [18], equilibrium optimization algorithm [19], firefly algorithm [20], sine cosine algorithm [21], tabu search algorithm [22], and ant-colony search [23].

Sunflower Optimizer (SFO) is a novel technique that is introduced by G. F. Gomes, et al. in 2019 in their work about identification of damage on laminated composite plates [24]. Other applications of SFO for parameter identification and state-of-charge estimation for lithium-polymer battery cells in Ref. [25], parameter estimation of three diode models of solar cell in Ref. [26], investigating the uncertainties due to the presence of distributed generation of wind power in Ref. [27]. SFO stimulated by the sunflowers movement towards the sunlight. The SFO is stimulated by the inverse-square law of radiation intensity, where the amount of heat is proportional to the squared distance between sunflowers and the sun.

Since, the present trend is towards fast meta-heuristic optimization algorithms for complex optimization problems. Network reconfiguration problem is still active and continues with the employment of these techniques. The recent SFO algorithm has been proposed to address the network reconfiguration problem. Besides, very few studies in the literature have been illustrated how to address the problem of topology variations with different solutions. An attempt has been made in this paper to tackle this issue through an improved graph theory-based radial power flow analysis.

The major contributions of the suggested work are outlined as follows:

- A recent SFO algorithm is applied to address the issue of distribution networks reconfiguration.

- An improved graph theory-based radial power flow analysis is proposed to deal with topology variations problem.

- The Backward/forward sweep (BFS) technique is used to find the load flow analysis.

- The SFO technique is proposed to handle the problem with the objective of maximizing the percentage of active power loss reduction.

- The suggested SFO is validated on the standard 33, 69bus and large scale 119-bus test systems.

- A comparison study is employed to show the capability of the proposed SFO. The findings show the effectiveness of the proposed approach to solve the complicated problem of distribution networks reconfiguration.

The remaining portion of this paper is organized as follows: The below section describes the problem formulation of distribution networks reconfiguration. It includes the power flow analysis, the objective function, and its constraints. The overview of SFO and its implementation for the predefined problem is presented in Section III. The numerical results are shown in Section IV. Finally, the conclusions' part is given in Section V.

\section{Problem formulation}

\section{A. Load Flow Analysis}

In power distribution systems, load flow analysis can be regarded as the most effective tool. Addressing the problem of optimal topology reconfiguration begins with determining the load flow solution of the network. One of the most suitable and efficient methods suggested to address radial distribution systems' load flow problem is the backward/forward sweep method. There are two significant modes: first, in the backward sweep mode, determining currents at all nodes from the terminal ends towards the main bus. While in the second mode (forward sweep), the corresponding node voltages are calculated from the main bus towards the terminal nodes [28].

The power flow technique should be capable to efficiently reflect the topology changes imposed by network reconfiguration. Hence, an improved graph theory is proposed to address the configuration variations problem. The 
computation procedures evolved in the algorithm are as follows:

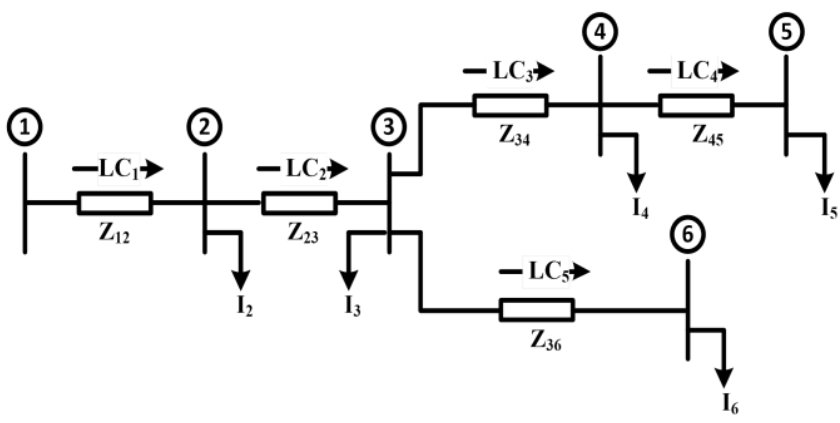

Fig. 1. Typical radial distribution network.

Procedure \#1: Enter the input data, including branch data (resistance \& reactance) between the buses, and load data (active and reactive power at the load bus).

Procedure \#2: Identify the open tie switches; to delete the open lines from [Line Data].

Procedure \#3: Plot an undirected graph that represents the network's new configuration.

Procedure \#4: Find the end terminals in the network.

Procedure \#5: Obtain the different paths to the end terminals from the source (bus \#1). Each end terminal has a single path from the source.

Procedure \#6: Determine the complete trace, [All_trace], comprising all paths.

Procedure \#7: Editing the [All_trace] to consist of two columns. Each row represents a branch; the first column specifies the beginning (From bus number) while the second indicates the branch end (To bus number). Then delete all rows that contain the source bus (bus \#1) in the second column.

Procedure \#8: Transfer the line parameters of each line in [Branch data], $(\mathrm{R} \& \mathrm{X})$, to the opposite lines in [All_trace].

Procedure \#9: Reorder the load buses, the second column in [All_trace], in ascending order.

Procedure \#10: Implement the BFS technique, as explained below:

Assume a typical six nodes radial distribution network as displayed in Fig. 1. The node voltages and branch currents are evaluated employing the BFS approach. Equivalent current injected at $a b^{\text {th }}$ node can be estimated as in (1),

$$
I_{b}=\frac{s_{b}^{*}}{V_{b}^{*}}
$$

where, $\mathrm{b}=2,3, \ldots, \mathrm{n} ; S_{i}^{*}$ is the conjugate of the apparent power of $b^{\text {th }}$ bus, $V_{b}^{*}$ is the conjugate of $\mathrm{i}^{\text {th }}$ bus voltage, and " $\mathrm{n}$ " reflects the overall number of the network buses.

- Formalization of BILC matrix

The line currents matrix [LC] can be estimated as,

$\mathrm{LC}_{5}=\mathrm{I}_{6}$

$\mathrm{LC}_{4}=\mathrm{I}_{5}$

$\mathrm{LC}_{3}=\mathrm{I}_{4}+\mathrm{I}_{5}$

$\mathrm{LC}_{2}=\mathrm{I}_{6}+\mathrm{I}_{5}+\mathrm{I}_{4}+\mathrm{I}_{3}$

$\mathrm{LC}_{1}=\mathrm{I}_{6}+\mathrm{I}_{5}+\mathrm{I}_{4}+\mathrm{I}_{3}+\mathrm{I}_{2}$

where, $I_{2}, I_{3}, \ldots, I_{6}$ are the equivalent current injection of corresponding nodes.

$$
\left[\begin{array}{l}
L C_{1} \\
L C_{2} \\
L C_{3} \\
L c_{4} \\
L C_{5}
\end{array}\right]=\left[\begin{array}{lllll}
1 & 1 & 1 & 1 & 1 \\
0 & 1 & 1 & 1 & 1 \\
0 & 0 & 1 & 1 & 0 \\
0 & 0 & 0 & 1 & 0 \\
0 & 0 & 0 & 0 & 1
\end{array}\right]\left[\begin{array}{c}
I_{2} \\
I_{3} \\
I_{4} \\
I_{5} \\
I_{6}
\end{array}\right]
$$

This equation can be rewritten as follow,

$$
[L C]=[B I L C][I]
$$

where, $[B I L C]$ denotes the relationship between the node current injections and line currents.

\section{- Formulization of LCBV Matrix}

The node voltages can be estimated from the main node in the direction of the terminal one posterior to compute the current injection by all loads while the line currents are calculated initiating from the final bus in the direction of the main. The matrix that determines the correlation between the line currents and node voltages can be defined as follow:

$$
[\mathrm{LCBV}]=[\mathrm{BILC}]^{\mathrm{T}}\left[\mathrm{Z}_{\mathrm{D}}\right]
$$

where, "T" refers to the transpose operator of the matrix, and $\left[\mathrm{Z}_{\mathrm{D}}\right]$ is a diagonal matrix having the line impedances as seen in (5).

$$
Z_{D}=\left[\begin{array}{lllll}
Z_{1} & 0 & 0 & 0 & 0 \\
0 & Z_{2} & 0 & 0 & 0 \\
0 & 0 & Z_{3} & 0 & 0 \\
0 & 0 & 0 & Z_{4} & 0 \\
0 & 0 & 0 & 0 & Z_{5}
\end{array}\right]
$$

where, $Z_{1}, \ldots, Z_{5}$ are the corresponding line impedances.

Finally, [LCBV] matrix can be defined as follow:

$$
\mathrm{Z}_{\mathrm{D}}=\left[\begin{array}{ccccc}
\mathrm{Z}_{1} & 0 & 0 & 0 & 0 \\
\mathrm{Z}_{1} & \mathrm{Z}_{2} & 0 & 0 & 0 \\
\mathrm{Z}_{1} & \mathrm{Z}_{2} & \mathrm{Z}_{3} & 0 & 0 \\
\mathrm{Z}_{1} & \mathrm{Z}_{2} & \mathrm{Z}_{3} & \mathrm{Z}_{4} & 0 \\
\mathrm{Z}_{1} & \mathrm{Z}_{2} & 0 & 0 & \mathrm{Z}_{5}
\end{array}\right]
$$

After that, the node voltages can be found by employing the [LCBV] and [LC] matrices.

$$
\left[\begin{array}{l}
V_{2} \\
V_{3} \\
V_{4} \\
V_{5} \\
V_{6}
\end{array}\right]=\left[\begin{array}{l}
V_{1} \\
V_{1} \\
V_{1} \\
V_{1} \\
V_{1}
\end{array}\right]-\left[\begin{array}{lllll}
\mathrm{Z}_{1} & 0 & 0 & 0 & 0 \\
\mathrm{Z}_{1} & \mathrm{Z}_{2} & 0 & 0 & 0 \\
\mathrm{Z}_{1} & \mathrm{Z}_{2} & \mathrm{Z}_{3} & 0 & 0 \\
\mathrm{Z}_{1} & \mathrm{Z}_{2} & \mathrm{Z}_{3} & \mathrm{Z}_{4} & 0 \\
\mathrm{Z}_{1} & \mathrm{Z}_{2} & 0 & 0 & \mathrm{Z}_{5}
\end{array}\right]\left[\begin{array}{l}
L C_{1} \\
L C_{2} \\
L C_{3} \\
L C_{4} \\
L C_{5}
\end{array}\right]
$$

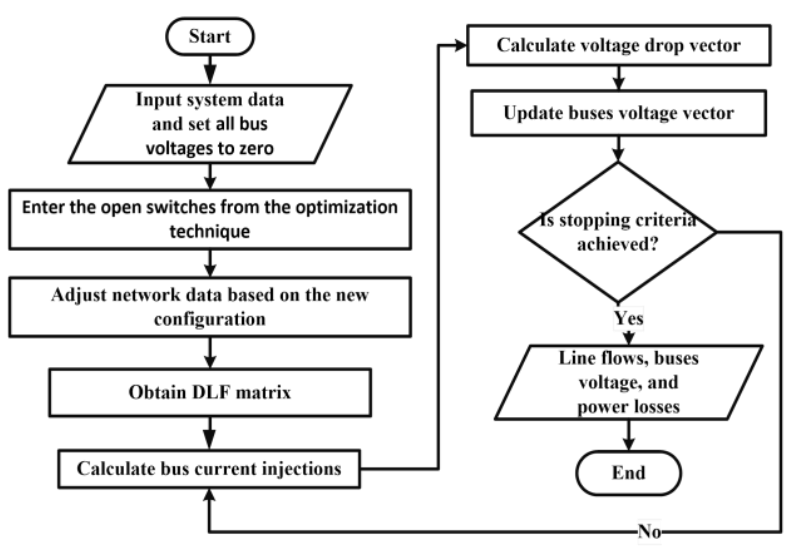

Fig. 2. Flow chart for power flow analysis. 


$$
\left[\begin{array}{l}
V_{1} \\
V_{1} \\
V_{1} \\
V_{1} \\
V_{1}
\end{array}\right]-\left[\begin{array}{l}
V_{2} \\
V_{3} \\
V_{4} \\
V_{5} \\
V_{6}
\end{array}\right]=\left[\begin{array}{lllll}
\mathrm{Z}_{1} & 0 & 0 & 0 & 0 \\
\mathrm{Z}_{1} & \mathrm{Z}_{2} & 0 & 0 & 0 \\
\mathrm{Z}_{1} & \mathrm{Z}_{2} & \mathrm{Z}_{3} & 0 & 0 \\
\mathrm{Z}_{1} & \mathrm{Z}_{2} & \mathrm{Z}_{3} & \mathrm{Z}_{4} & 0 \\
\mathrm{Z}_{1} & \mathrm{Z}_{2} & 0 & 0 & \mathrm{Z}_{5}
\end{array}\right]\left[\begin{array}{l}
L C_{1} \\
L C_{2} \\
L C_{3} \\
L C_{4} \\
L C_{5}
\end{array}\right]
$$

This can be presented as follow:

$$
[\Delta V]=[L C B V][L C]
$$

where, [LCBV] denotes the relationship between the line currents injections and nodes voltage.

$$
\begin{aligned}
& {[\Delta V]=[L C B V][B I L C][I]} \\
& {[\Delta V]=[D L F][I]}
\end{aligned}
$$

where, $[D L F]$ indicates the relation between the node current injections and the voltage reduction.

To obtain the load flow analysis, the next equations must be solved iteratively.

$$
\begin{aligned}
I_{i}^{K} & =\left(\frac{s_{i}}{V_{i}^{K}}\right)^{*} \\
{\left[\Delta V^{K+1}\right] } & =[D L F]\left[I^{K}\right] \\
{\left[V^{K+1}\right] } & =\left[V_{o}\right]-\left[\Delta V^{K+1}\right]
\end{aligned}
$$

where, $\left[V_{o}\right]$ is the initial vector of the node voltages.

This approach is reiterated till the convergence is achieved. The total active power loss can be determined as in (14).

$$
P_{\text {loss }}=[R]^{T} \times|[B I L C] \times[I]|^{2}
$$

Fig. 2 shows a complete power flow analysis in the form of a flow chart.

\section{B. Objective Function}

The principal objective in this study is formulated to find the maximum percentage of real power loss reduction that resulting from network reconfiguration.

$$
\text { Objective function }=\max (\mathrm{PLR} \%)
$$

where, PLR\% is the percentage of real power loss $\left(P_{\text {loss }}\right)$ decrease which may be computed by calculating the difference between the active power loss before and after reconfiguration divided by the initial value.

$$
P L R \%=\frac{\left(P_{\text {loss }_{\text {before }}}-P_{\text {loss }_{\text {after }}}\right)}{P_{\text {loss }_{\text {before }}}} \times 100
$$

\section{Constraints}

The objective function must be achieved with the following limitations:

1) Bus voltage limitation

The voltage value at each node should be within preset margins $( \pm 10 \%)$.

$$
\left|V_{\min }\right| \leq\left|V_{i}\right| \leq\left|V_{\max }\right| ; i=1,2,3, \ldots, \text { nbus }
$$

2) Branch current limitation

The current in each line must be in its acceptable limit.

$$
0 \leq\left|I_{k}\right| \leq\left|I_{\text {max }, k}\right| ; k=1,2,3, \ldots, \text { mbranch }
$$

\section{3) Radial configuration}

A feasible network topology must be radial, and it should not include any islanded node. Network radiality can be verified as follow:

- Obtain the incidence matrix.

- Each element $\left(k_{m, n}\right)$ in this matrix, is found by (19).

$$
k_{m, n}=\left\{\begin{array}{lr}
0 & \text { if line } m \text { is not connected to node } n \\
1 & \text { if line } m \text { is directed away from node } n \\
-1 & \text { if line } m \text { is directed toward node } n
\end{array}\right.
$$

- Eliminate the column of the reference bus (the $1^{\text {st }}$ ), and the consequent square matrix is described by $\mathrm{A}$.

- Compute the determinant of matrix A. The network has a radial topology in case of the determinant equals 1 or -1 . While, if the determinant is zero, this ensures that the network configuration is mesh, or some loads are not energized (isolated).

\section{SUNFLOWER APPROACH}

\section{A. Sunflower optimizer}

Sunflower Optimizer is a novel technique that is introduced by G. F. Gomes, et al. in 2019 [24]. It imitates the orientations of sunflower plants toward the sun. Through the motion, flowering can occur between the nearest adjacent sunflowers. The total received radiation (radiation intensity) depends upon its position from the sun for each sunflower. Besides, increasing the spacing between the sun and the plants will lower the received radiation from the sun based on the inverse square low radiation, as seen in (20).

$$
Q_{i}=\frac{G}{4 \pi r_{i}^{2}}
$$

where, $Q_{i}$ is the amount of radiation received by each plant, $\mathrm{G}$ is the sun's radiation intensity, and $r_{i}$ is the separation between each plant and the sun.

All plants regulate their orientation to the sun, according to (21).

$$
\overrightarrow{S_{l}}=\frac{X^{*}-X_{i}}{\left\|X^{*}-X_{i}\right\|} ; i=1,2, \ldots, n_{p}
$$

where, $X^{*}, X_{i}$, and $n_{p}$ refer to the optimum, present value of the solution, and the solutions number (number of plants), respectively.

The step of sunflowers (individuals) towards the sun measured by:

$$
d_{i}=\lambda \times P_{i}\left(\left\|X_{i}+X_{i-1}\right\|\right) \times\left\|X_{i}+X_{i-1}\right\|
$$

where, $\lambda$ is the constant value referring to the plant's "inertial" displacement and $P_{i}\left(\left\|X_{i}+X_{i-1}\right\|\right)$ is the probability of the fecundation that each plant (i) can inoculate the nearest neighbor (i-1) to create a novel generation of plants in an updated random position based on the distance between the sunflowers.

Plant steps are constrained to avert surpass the following value.

$$
d_{\max }=\frac{\left\|X_{\max }-X_{\min }\right\|}{2 \times n_{p}}
$$

where, $X_{\max }$ and $X_{\min }$ are the higher and lower boundaries, respectively.

To create a new generation of sunflowers, each plant (i) updates its position based on (22) and (23).

$$
\vec{X}_{i+1}=\vec{X}_{i}+d_{i} \times \vec{s}_{i}
$$

where, $\vec{X}_{i+1}$ refers to the location of the newly plants. 
B. Implementation of SFO to distribution network reconfiguration problem

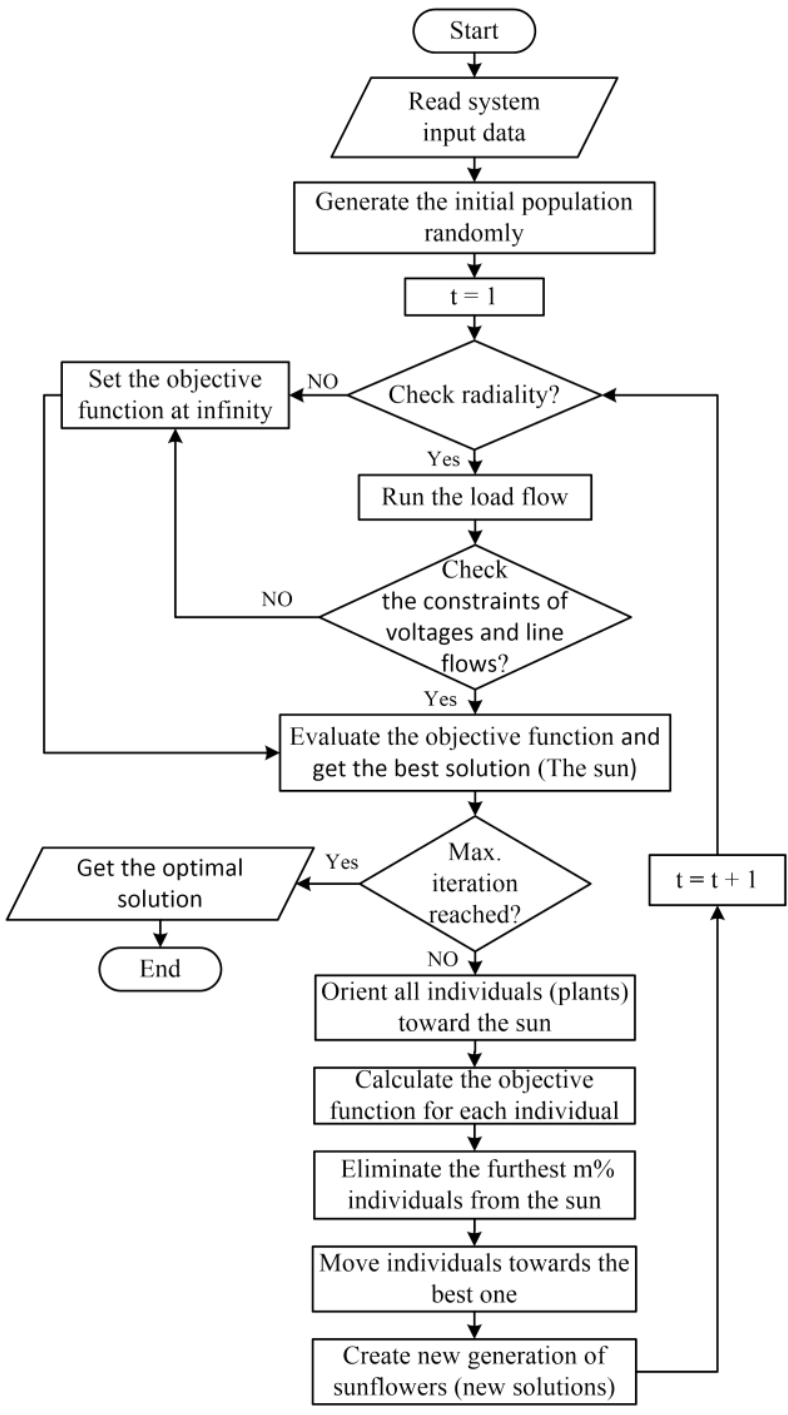

Fig. 3. Flow chart of applying SFO algorithm.

Fig. 3. shows the application procedures of the SFO approach to solving the issue of finding the optimal configuration of the distribution system are described below:

Procedure \#1: Input the problem data; the plants number (population size), the iterations number, the loops that will be created by locking the tie/open switches, network data.

Procedure \#2: Initialize an arbitrary population. Each plant (individual) denotes a feasible solution. Then set the iteration number $(\mathrm{t}=1)$.

Procedure \#3: Check the radiality constraint to ensure that the proposed topology is radial and there is not any load point energizes from two alternative paths. If the radiality constraint is failed, set the fitness function at infinity.

Procedure \#4: Run the load flow with the help of the improved graph theory and BFS technique. Evaluate the constraints for voltages and line flows.

Procedure \#5: Check the voltages and current constraints. Also, if any constraint is failed, set the fitness function at infinity.
Procedure \#6: Assess the fitness function (maximum the real power loss decrease percentage) in (15) for each solution and determine the optimum solution (The sun).

Procedure \#7: If reached the maximum iteration number, print the optimum solution. If not, go to the next procedure.

Procedure \#8: Orient all sunflowers toward the sun using (21).

Procedure \#9: Evaluate the fitness function for each solution then delete the worst $\mathrm{m} \%$ individuals.

Procedure \#10: Calculate the step for each sunflower using (22).

Procedure \#11: Check the maximum step of sunflowers based on (23).

Procedure \#12: Upgrade the solutions using (24).

Procedure \#13: Add one to the iteration number.

Procedure \#14: Go to procedure \#3.

\section{NETWORKS DESCRIPTION AND RESULTS}

Three test networks are presented to assess the suggested SFO technique's efficacy: IEEE 33, 69 and 119-bus networks. The presented approach has been applied with the help of Matlab program.

\section{A. Test Systems Description}

\section{1) Test Network I}

The first applied network in this study is the IEEE 33-bus system [8]. It is operating at a voltage level of $12.66 \mathrm{kV}$. Fig. 4 displays the single line diagram of the system. It consists of 37 branches: five of them are tie switches while the others are sectionalizing switches. The total active and reactive power demand are 3.715 MW and 2.3 MVAr, respectively.

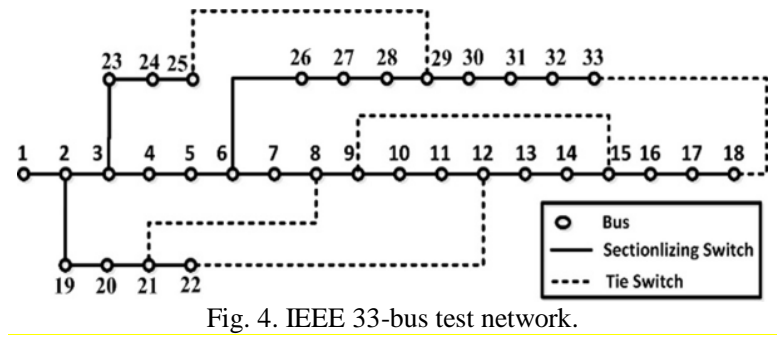

\section{2) Test Network II}

The second applied network is the IEEE 69-bus system which running at a voltage of $12.66 \mathrm{kV}$ [8]. It consists of 73 branches: five of them are tie switches while the others are sectionalizing switches as shown in Fig. 5. The total active and reactive power demand are 3.8014 MW and 2.6936 MVAr, respectively.

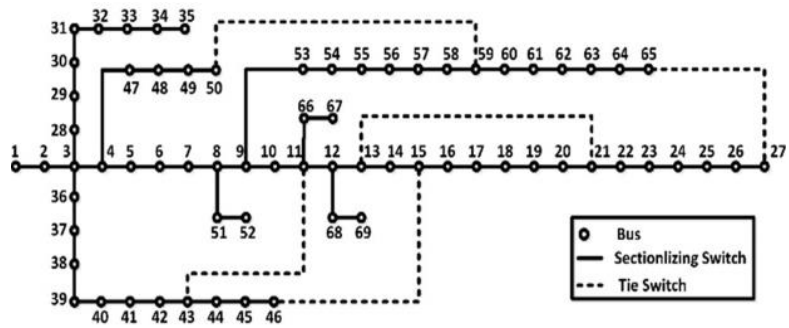

Fig. 5. IEEE 69-bus test network. 


\section{3) Test Network III}

To ensure the reliability of the proposed methodology, large power system of 119-bus system is analyzed [29]. It is running at a voltage of $11 \mathrm{kV}$. It contains 118 sectionalizing switches and 15 tie switches as displayed in Fig. 6. The total active and reactive power demand are 22.7097 MW and 17.0411 MVAr, respectively.

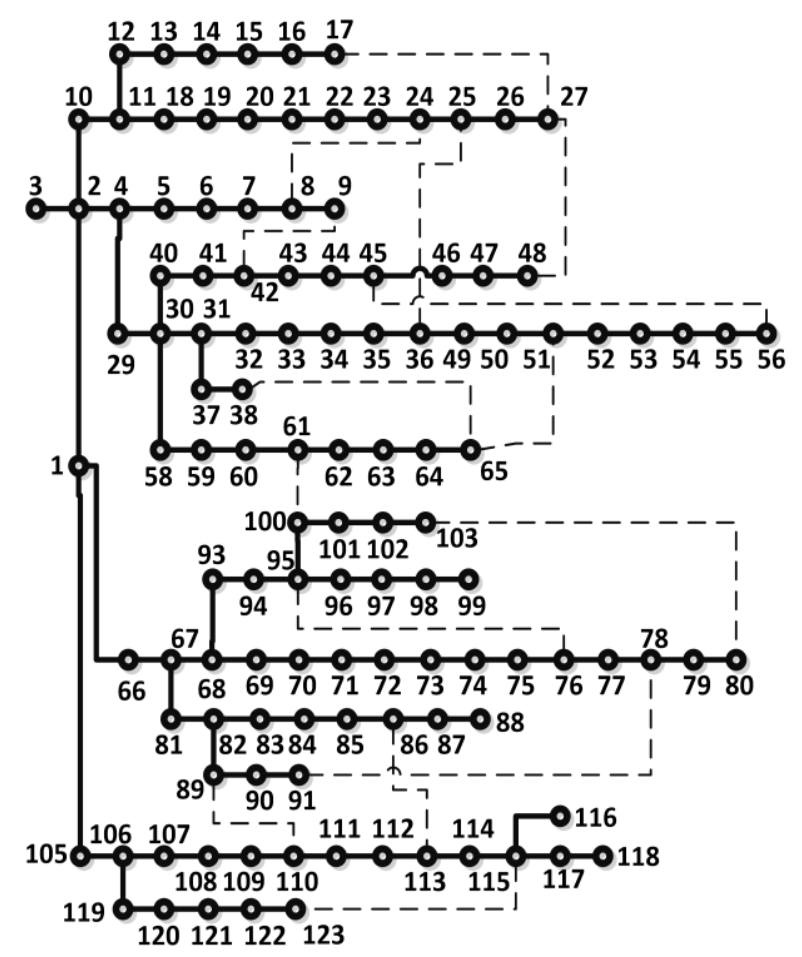

Fig. 6. IEEE 119-bus test network.

\section{B. Test Results}

\section{1) Loop Vectors}

By locking all tie/open switches, the primary loops in each system can be identified. The fundamental loops number and the number of tie/open switches included in the system are identical. Some switches belong to the same two fundamental loops, so it must be deleted from one of them. Based on the system topology, Table I tabulates the principal loops of the first two test networks.

TABLE I

\begin{tabular}{c||c||c}
\multicolumn{1}{c||}{ Loop } & $\begin{array}{c}\text { NETWORK LOOPS OF NETWORKS I AND II } \\
\text { NETWORK I }\end{array}$ & Network II \\
\hline L1 & $8,9,10,11,21,33,35$ & $11,12,13,14,43,44,45,71$ \\
\hline \multirow{2}{*}{ L2 } & $2,3,4,5,6,7,18,19,20$ & $\begin{array}{c}4,5,6,7,8,46,47,48,49, \\
52,53,54,55,56,57,58\end{array}$ \\
\hline \multirow{2}{*}{$\mathbf{L 3}$} & $12,13,14,34$ & $\begin{array}{c}3,9,10,35,36,37,38,39, \\
40,41,42,69\end{array}$ \\
\hline \multirow{2}{*}{$\mathbf{L 4}$} & $\begin{array}{c}15,16,17,29,30,31,36, \\
32\end{array}$ & $\begin{array}{c}21,22,23,24,25,26,59,60, \\
61,62,63,64,73\end{array}$ \\
\hline \multirow{2}{*}{$\mathbf{L 5}$} & $\begin{array}{c}22,23,24,25,26,27,28, \\
37\end{array}$ & $15,16,17,18,19,20,70$
\end{tabular}

\section{2) Test Network I}

The technical results of implementing the proposed SFO are tabulated in Table II. Initially (before the reconfiguration), the original topology includes five tie switches (switches $33-37$ ). Each tie switch comprise a loop vector as tabulates in Table II. only one switch must be opened in each loop. Besides, the radiality constraint of the network is checked using (23) before running the load flow program. If the network topology is not radial, no need for load flow step. By applying the BFS, the active power loss is $202.67 \mathrm{~kW}$ in the base case.

TABLE II

\begin{tabular}{|c|c|c|c|c|c|}
\hline & & $\begin{array}{c}\text { Open } \\
\text { Switches }\end{array}$ & $\begin{array}{c}\mathbf{P}_{\text {loss }} \\
(\mathbf{k W})\end{array}$ & $\underset{\%}{\text { PLR }}$ & $\begin{array}{c}\mathbf{V}_{\min } \\
\text { (P.U.), } \\
\text { \# bus }\end{array}$ \\
\hline \multirow{2}{*}{$\begin{array}{c}\text { Test } \\
\text { Network } \\
\text { I }\end{array}$} & $\begin{array}{c}\text { The base } \\
\text { case }\end{array}$ & $\begin{array}{c}33,34,35 \\
36,37\end{array}$ & 202.67 & - & $\begin{array}{c}0.913 \\
\# 18\end{array}$ \\
\hline & $\begin{array}{l}\text { The } \\
\text { proposed } \\
\text { SFO }\end{array}$ & $\begin{array}{c}9,7,14 \\
32,37\end{array}$ & 139.53 & 31 & $\begin{array}{c}0.937 \\
\# 32\end{array}$ \\
\hline \multirow{2}{*}{$\begin{array}{c}\text { Test } \\
\text { Network } \\
\text { II }\end{array}$} & $\begin{array}{c}\text { The base } \\
\text { case }\end{array}$ & $\begin{array}{c}69,70,71 \\
72,73\end{array}$ & 224.96 & - & $\begin{array}{c}0.917, \\
\# 65\end{array}$ \\
\hline & $\begin{array}{c}\text { The } \\
\text { proposed } \\
\text { SFO }\end{array}$ & $\begin{array}{c}14,55,61 \\
69,70\end{array}$ & 98.59 & 56 & $\begin{array}{c}0.949 \\
\# 61\end{array}$ \\
\hline \multirow{2}{*}{$\begin{array}{c}\text { Test } \\
\text { Network } \\
\text { III }\end{array}$} & $\begin{array}{c}\text { The base } \\
\text { case }\end{array}$ & $\begin{array}{c}119,120 \\
121,122, \\
123,124 \\
125,126 \\
127,128 \\
129,130 \\
131,132 \\
133\end{array}$ & 1294.3 & - & $\begin{array}{c}0.866 \\
\# 116\end{array}$ \\
\hline & $\begin{array}{l}\text { The } \\
\text { proposed } \\
\text { SFO }\end{array}$ & $\begin{array}{c}23,27,33, \\
40,43,49, \\
52,62, \\
72,74,77, \\
83,110 \\
126,131\end{array}$ & 865.32 & 33 & $\begin{array}{c}0.932 \\
\# 111\end{array}$ \\
\hline
\end{tabular}

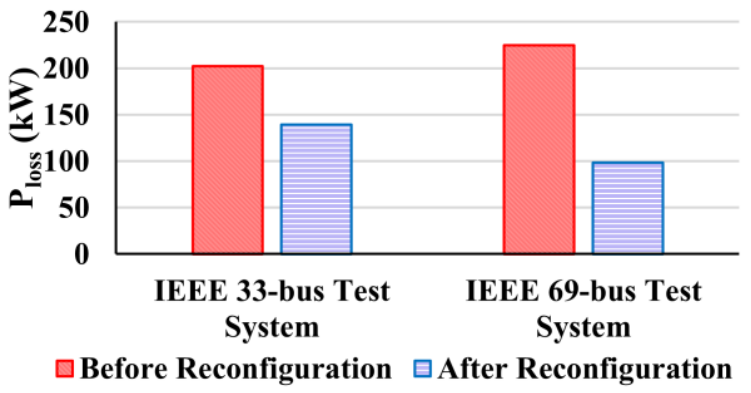

Fig. 7. Comparison between the active power loss before and after reconfiguration of the two test networks.

In comparison, after applying the SFO algorithm to determine the test network's optimal topology, the active power loss is decreased to $139.53 \mathrm{~kW}$ as depicted in Fig. 7. The optimum solution is achieved by opening the switches 9, $7,14,32$, and 37 that caused a maximum real power loss decrease percentage reaches $31.15 \%$. Fig. 8 shows the IEEE 33-bus test network topology after reconfiguration. Besides, Fig. 9 shows the voltage profile before and after network reconfiguration. It is clear that the results obtained after 
reconfiguration are better than those of the base case. The minimum voltage bus is substantially boosted to 0.938 P.U. at node \# 32.

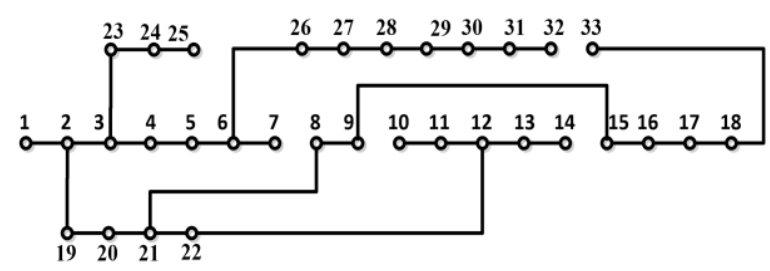

Fig. 8. IEEE 33-bus test network after reconfiguration.

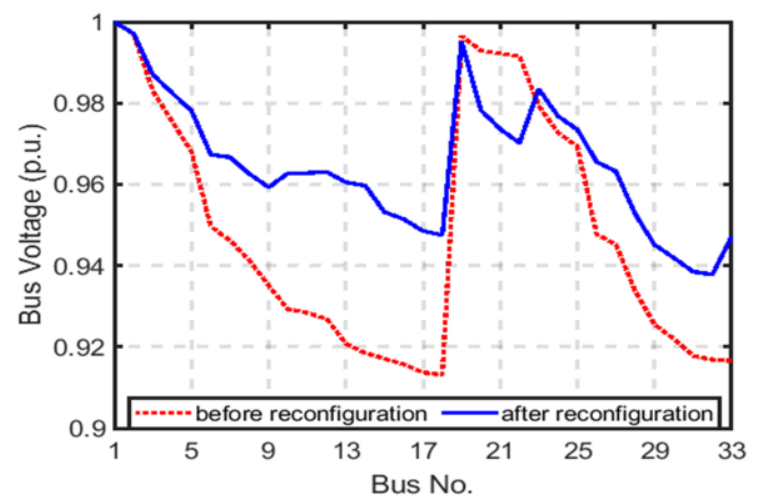

Fig. 9. Voltage profile of 33-bus distribution network.

\section{3) Test Network II}

Similarly, the technical results of implementing the suggested SFO on the second test network are listed in Table II. In the original case, before the reconfiguration, the test system has five loops or tie switches (switches 69-73) with a real power loss of $224.96 \mathrm{~kW}$. While after applying the SFO algorithm, the real power loss is declined to $98.59 \mathrm{~kW}$ as shown in Fig. 7. The objective function is maximized by opening three sectionalizing switches; 14, 55, 61 and closing three tie switches; 71, 72 and 73. The percentage of real power loss decrease is maximized to $56.17 \%$. Fig. 10 shows the IEEE 69-bus test network topology after reconfiguration. Further, Fig. 11 shows the voltage profile enhancement wherein the minimum voltage node is increased from 0.917 P.U. at bus 65 to 0.949 P.U. at node 61 .

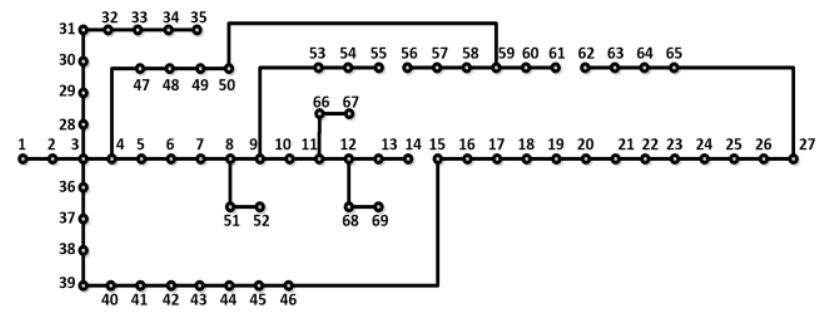

Fig. 10. IEEE 69-bus test network after reconfiguration.

\section{4) Test Network III}

Table II presents the results of applying the proposed SFO on the third test network. Initially, the test network includes 15 tie switches (switches 119-133). The initial real power loss is $1294.9 \mathrm{~kW}$. While after network reconfiguration using SFO, the final open switches are 23, 27, 33, 40, 43, 49, 52, 62, 72,
$74,77,83,110,126,131$. Fig. 12 show the single line diagram of IEEE 119-bus test network after reconfiguration. The active power loss is reduced to $865.32 \mathrm{~kW}$, which means that power losses are reduced by $429.58 \mathrm{~kW}$. The objective function, percentage reduction of real power loss, is maximized to $33 \%$.

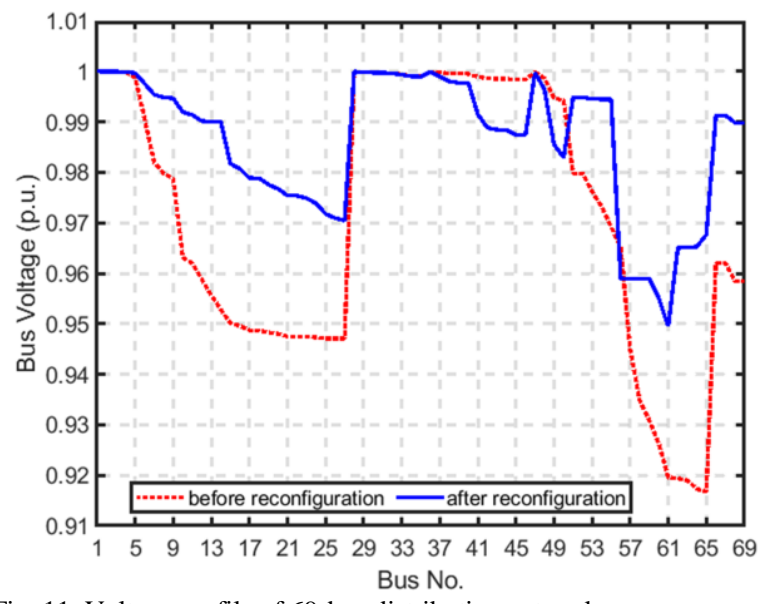

Fig. 11. Voltage profile of 69-bus distribution network.

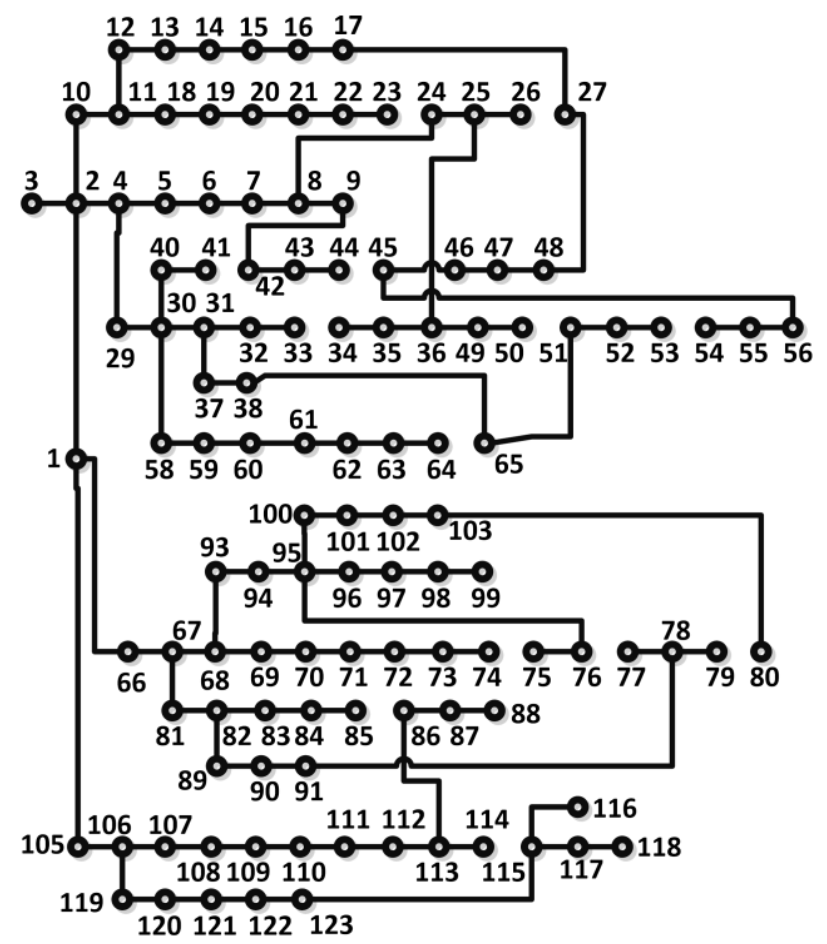

Fig. 12. IEEE 119-bus test network after reconfiguration.

Fig. 13 shows the voltage profile improvement achieved by the proposed network reconfiguration algorithm. As shown, most of the bus voltages have been improved after network reconfiguration. The test results show that before reconfiguration, the minimum bus voltage was 0.866 P.U. at bus \#116 and after reconfiguration, it is significantly enhanced to 0.932 P.U. at bus \#111. 


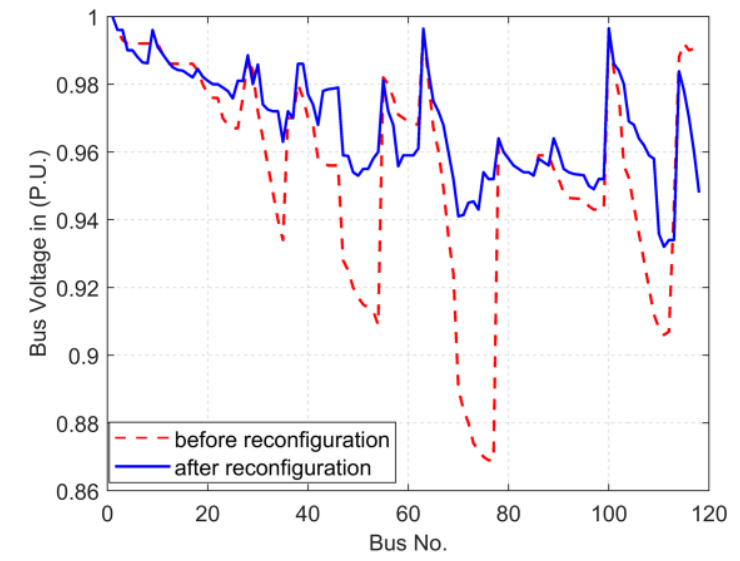

Fig. 13. Voltage profile of 119-bus distribution network.

\section{Comparison with other optimization methods}

Tables III, IV and V present a comparison of the optimal topologies obtained for the test networks employing the suggested SFO algorithm with other techniques available in the literature. Figs. 14 and 15 show that the optimal solution's real power loss is either the same or better than those of other techniques. Besides, the comparison results of the IEEE 119bus system ensure the priority of the proposed SFO than the other methods. This confirms the capability and effectiveness of the proposed SFO algorithm for different scale distribution networks.

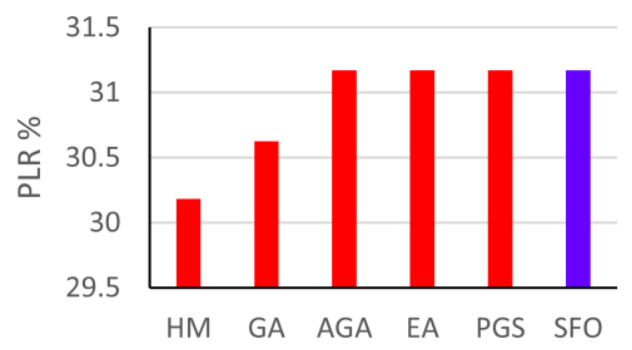

Fig. 14. Comparison with other optimization methods based on the objective function for IEEE 33-bus test system.

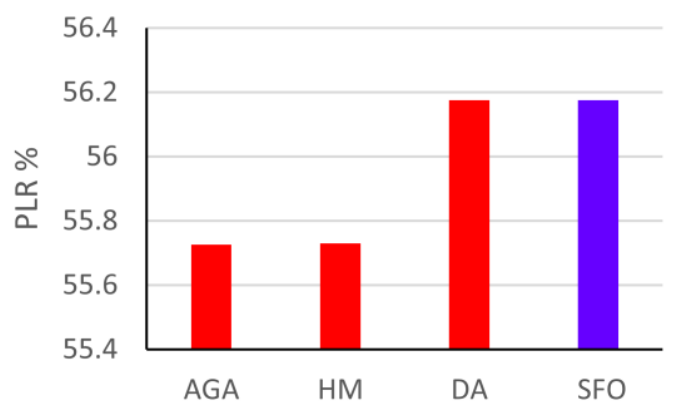

Fig. 15. Comparison with other optimization methods based on the objective function for IEEE 69-bus test system.
TABLE III

RESULTS OF COMPARING SFO WITH OTHER OPTIMIZATION METHODS FOR IEEE 33-BUS TEST SYSTEM

\begin{tabular}{c||c||c}
$\begin{array}{c}\text { Optimization } \\
\text { Method }\end{array}$ & Open Switches & $\begin{array}{c}\mathbf{P}_{\text {loss }} \\
(\mathbf{k W})\end{array}$ \\
\hline Base Case & $33,34,35,36,37$ & 202.67 \\
\hline $\begin{array}{c}\text { Heuristic Method } \\
\text { (HM) [33] }\end{array}$ & $7,10,14,33,37$ & 141.5 \\
\hline $\begin{array}{c}\text { Genetic Algorithm } \\
\text { (GA) [14] }\end{array}$ & $9,28,33,34,36$ & 140.6 \\
\hline $\begin{array}{c}\text { Refined Genetic } \\
\text { Algorithm (RGA) } \\
{[\mathbf{1 3 ]}}\end{array}$ & $7,9,14,32,37$ & 139.5 \\
\hline $\begin{array}{c}\text { Evolutionary } \\
\text { Algorithm (EA) [34] }\end{array}$ & $7,9,14,32,37$ & 139.5 \\
\hline $\begin{array}{c}\text { Plant Growth } \\
\text { Simulation (PGS) } \\
{[\mathbf{1 7 ]}}\end{array}$ & $7,9,14,32,37$ & 139.5 \\
\hline $\begin{array}{c}\text { The proposed SFO } \\
\text { The }\end{array}$ & $7,9,14,32,37$ & 139.5 \\
\hline
\end{tabular}

TABLE IV

RESULTS OF COMPARING SFO WITH OTHER OPTIMIZATION METHODS FOR IEEE 69-BUS TEST SYSTEM

\begin{tabular}{c||c||c}
$\begin{array}{c}\text { Optimization } \\
\text { Method }\end{array}$ & Open Switches & $\begin{array}{c}\mathbf{P}_{\text {loss }} \\
(\mathbf{k W})\end{array}$ \\
\hline Base Case & $69,70,71,72,73$ & 224.96 \\
\hline $\begin{array}{c}\text { Adaptive Genetic } \\
\text { Algorithm (AGA) } \\
{[30]}\end{array}$ & $15,58,62,70,71$ & 99.6 \\
\hline $\begin{array}{c}\text { Heuristic Method } \\
\text { (HM) [31] }\end{array}$ & $14,56,63,69,70$ & 99.59 \\
\hline $\begin{array}{c}\text { Decentralized } \\
\text { approach (DA) [32] }\end{array}$ & $14,58,61,69,70$ & 98.59 \\
\hline The proposed SFO & $14,55,61,69,70$ & 98.59 \\
\hline
\end{tabular}

TABLE V

RESULTS OF COMPARING SFO WITH OTHER OPTIMIZATION METHODS FOR IEEE 119-BUS TEST SYSTEM

\begin{tabular}{c||c||c}
$\begin{array}{c}\text { Optimization } \\
\text { Method }\end{array}$ & Open Switches & $\begin{array}{c}\mathbf{P}_{\text {loss }} \\
(\mathbf{k W})\end{array}$ \\
\hline Base Case & $119,120,121$, & 1294.3 \\
& $122,123,124$, & \\
& $125,126,127$, & \\
$128,129,130$, & \\
$131,132,133$ & \\
\hline Particle swarm & $9,23,35,43,52$, & 898.6 \\
optimization [35] & $60,71,74,82,96$, & \\
& $99,110,120,122$, & \\
& 131 & \\
\hline Modified Tabu & $23,27,33,40,43$, & 884.9 \\
Search algorithm & $49,52,62,72,74$, & \\
{$[22]$} & $77,83,110,126$, & \\
& 131 & \\
\hline Minimum spanning & $23,26,34,39,42$, & 883.5 \\
tree algorithm [36] & $52,58,70$, & \\
& $73,75,95,109$, & \\
& $122,129,130$ & \\
\hline The proposed SFO & $23,27,33,40,43$, & 865.32 \\
& $49,52,62$, & \\
& $72,74,77,83$, & \\
& $110,126,131$ & \\
\hline
\end{tabular}




\section{Conclusions}

In this paper, The SFO algorithm has been successfully applied for distribution network reconfiguration problem. The main objective is formulated to achieve the maximum real power loss decrease. The effectiveness of proposed method is demonstrated on IEEE 33, 69 and 119-bus networks. To obtain the load flow solution, an efficient approach is applied called Backward/forward sweep. The base case real power losses are $202.67 \mathrm{~kW}, 224.96$ and $1294.3 \mathrm{~kW}$ for the IEEE 33, 69 and 119-bus networks, respectively. Besides, an improved graph theory is developed to address the configuration variations problem. The proposed SFO method is characterized by effectiveness and simplicity. The obtained results via MATLAB program revealed that the SFO algorithm could achieve the maximum percentage of active loss decrease. The power losses are reduced to $139.53 \mathrm{~kW}$, $98.59 \mathrm{~kW}$, and $865.32 \mathrm{~kW}$, for the three test networks, respectively. The proposed SFO did not only increase the losses reduction, but also improved the voltage profile of the test networks. The simulated results on the medium and largescale systems like 69-node and 119-node distribution systems have shown that the applicability of SFO is more noticeable. Thus, the proposed method can be applied to any large-scale practical radial distribution networks.

\section{REFERENCES}

[1] A. Mendes, P. M. Franca, C. Lyra, C. Pissarra, and C. Cavellucci, "Capacitor placement in large-sized radial distribution networks," IEE Proc. - Gener. Transm. Distrib., vol. 152, no. 4, p. 496, 2005, doi: 10.1049/ip-gtd:20059015.

[2] N. R. Battu, A. R. Abhyankar, and N. Senroy, "DG planning with amalgamation of operational and reliability considerations," Int. J. Emerg. Electr. Power Syst., vol. 17, no. 2, pp. 131-141, 2016, doi: 10.1515/ijeeps-2015-0142.

[3] A. A. Abdelsalam and H. S. E. Mansour, "Optimal Allocation and Hourly Scheduling of Capacitor Banks Using Sine Cosine Algorithm for Maximizing Technical and Economic Benefits," Electr. Power Components Syst., pp. 1-15, 2019, doi: 10.1080/15325008.2019.1629513.

[4] H. S. E. Mansour, A. A. Abdelsalam, M. Nabil, and A. A. Sallam, "Optimal Capacitor Banks Allocation in Distribution Systems with Distributed Generators Using Antlion Optimizer," in Nineteenth International Middle East Power Systems Conference (MEPCON), 2017, no. December, pp. 19-21.

[5] H. S. E. Mansour, A. A. Abdelsalam, and A. A. Sallam, "Optimal Distributed Energy Resources Allocation Using Ant-Lion Optimizer for Power Losses Reduction," in The 5th IEEE International Conference on Smart Energy Grid Engineering, 2017, pp. 346-352.

[6] S. Mishra, S. Paul, and D. Das, "A comprehensive review on power distribution network reconfiguration," Energy Syst., vol. 8, no. 2, pp. 227-284, 2017, doi: 10.1007/s12667-016-0195-7.

[7] S. Civanlar, J. J. Grainger, H. Yin, and S. S. H. Lee, "DISTRIBUTION FEEDER RECONFIGURATION FOR LOSS REDUCTION," IEEE Trans. Power Deliv., vol. 3, no. 3, pp. 1217-1223, 1999, doi: 10.1007/s004419900093.

[8] F. F. Wu and M. E. Baran, "Network reconfiguration in distribution systems for loss reduction and load balancing," IEEE Trans. Power Deliv., vol. 4, no. 2, pp. 1401-1407, 1989.

[9] M. A. Kashem, G. B. Jasmon, and V. Ganapathy, "New approach of distribution system reconfiguration for loss minimization," Int. J. Electr. Power Energy Syst., vol. 22, no. 4, pp. 269-276, 2000, doi: 10.1016/S0142-0615(99)00057-5.

[10] D. Shirmohammadi and H. W. Hong, "Reconfiguration of electric distribution networks for resistive line losses reduction," IEEE Trans. Power Deliv., vol. 4, no. 2, pp. 1492-1498, 1989, doi: 10.1109/61.25637.

[11] F. V. Gomes, S. Carneiro, J. L. R. Pereira, M. P. Vinagre, P. A. N.
Garcia, and L. A. Ramos, "A new heuristic reconfiguration algorithm for large distribution systems," IEEE Trans. Power Syst., vol. 20, no. 3, pp. 1373-1378, 2005, doi: 10.1109/TPWRS.2005.851937.

[12] D. Das, "A Fuzzy Multiobjective Approach for Network Reconfiguration of Distribution Systems," IEEE Trans. Power Deliv., vol. 21, no. 1, pp. 202-209, 2006.

[13] J. Z. Zhu, "Optimal reconfiguration of electrical distribution network using the refined genetic algorithm," Electr. Power Syst. Res., vol. 62, no. 1, pp. 37-42, 2002, doi: 10.1016/S0378-7796(02)00041-X.

[14] Y. Hong and S. Ho, "Determination of Network Configuration Considering Multiobjective in Distribution Systems Using Genetic Algorithms," IEEE Trans. POWER Syst., vol. 20, no. 2, pp. 1062-1069, 2005

[15] J. Mendoza, R. López, D. Morales, E. López, P. Dessante, and R. Moraga, "Minimal Loss Reconfiguration Using Genetic Algorithms With Restricted Population and Addressed Operators: Real Application," IEEE Trans. POWER Syst., vol. 21, no. 2, pp. 948-954, 2006.

[16] B. Enacheanu, B. Raison, R. Caire, O. Devaux, W. Bienia, and N. Hadjsaid, "Radial Network Reconfiguration Using Genetic Algorithm Based on the Matroid Theory," IEEE Trans. POWER Syst., vol. 23, no. 1, pp. 186-195, 2008.

[17] C. Wang and H. Z. Cheng, "Optimization of Network Configuration in Large Distribution Systems Using Plant Growth Simulation Algorithm," IEEE Trans. POWER Syst., vol. 23, no. 1, pp. 119-126, 2008.

[18] R. Pegado, Z. Ñaupari, Y. Molina, and C. Castillo, "Radial distribution network reconfiguration for power losses reduction based on improved selective BPSO," Electr. Power Syst. Res., vol. 169, no. January, pp. 206-213, 2019, doi: 10.1016/j.epsr.2018.12.030.

[19] A. M. Shaheen, A. M. Elsayed, R. A. El-Sehiemy, and A. Y. Abdelaziz, "Equilibrium optimization algorithm for network reconfiguration and distributed generation allocation in power systems," Appl. Soft Comput., vol. 98, p. 106867, 2021, doi: 10.1016/j.asoc.2020.106867.

[20] C. Gerez, L. I. Silva, E. A. Belati, A. J. Sguarezi Filho, and E. C. M. Costa, "Distribution Network Reconfiguration Using Selective Firefly Algorithm and a Load Flow Analysis Criterion for Reducing the Search Space," IEEE Access, vol. 7, pp. 67874-67888, 2019, doi: 10.1109/ACCESS.2019.2918480

[21] A. V Sudhakara Reddy and M. Damodar Reddy, "Network Reconfiguration of Distribution System for Maximum Loss Reduction Using Sine Cosine Algorithm," Int. J. Eng. Res. Appl. www.ijera.com, vol. 7, no. January 2017, pp. 34-39, 2017, doi: 10.9790/96220710073439.

[22] A. Y. Abdelaziz, F. M. Mohamed, S. F. Mekhamer, and M. A. L. Badr, "Distribution system reconfiguration using a modified Tabu Search algorithm," Electr. Power Syst. Res., vol. 80, no. 8, pp. 943-953, 2010, doi: 10.1016/j.epsr.2010.01.001.

[23] A. Y. Abdelaziz, R. a Osama, and S. M. Elkhodary, "Distribution Systems Reconfiguration Using Ant Colony Optimization and Harmony Search Algorithms," Electr. Power Components Syst., vol. 41, no. 5, pp. 537-554, 2013, doi: 10.1080/15325008.2012.755232.

[24] G. Ferreira, G. Sebastiao, C. Jr, A. Carlos, and A. Jr, "A sunflower optimization ( SFO ) algorithm applied to damage identification on laminated composite plates," Eng. Comput., vol. 35, no. 2, pp. 619-626, 2019, doi: 10.1007/s00366-018-0620-8.

[25] R. A. El-Sehiemy, M. A. Hamida, and T. Mesbahi, "Parameter identification and state-of-charge estimation for lithium-polymer battery cells using enhanced sunflower optimization algorithm," Int. J. Hydrogen Energy, vol. 45, no. 15, pp. 8833-8842, 2020, doi: 10.1016/j.jijhydene.2020.01.067.

[26] M. H. Qais, H. M. Hasanien, and S. Alghuwainem, "Identification of electrical parameters for three-diode photovoltaic model using analytical and sunflower optimization algorithm," Appl. Energy, vol. 250, no. May, pp. 109-117, 2019, doi: 10.1016/j.apenergy.2019.05.013.

[27] A. M. Shaheen, E. E. Elattar, R. A. El-Sehiemy, and A. M. Elsayed, "An Improved Sunflower Optimization Algorithm-Based Monte Carlo Simulation for Efficiency Improvement of Radial Distribution Systems Considering Wind Power Uncertainty," IEEE Access, vol. 9, pp. 23322344, 2021, doi: 10.1109/ACCESS.2020.3047671.

[28] a. Augugliaro, L. Dusonchet, S. Favuzza, M. G. Ippolito, and E. R. Sanseverino, "A backward sweep method for power flow solution in distribution networks," Int. J. Electr. Power Energy Syst., vol. 32, no. 4, pp. 271-280, 2010, doi: 10.1016/j.ijepes.2009.09.007.

[29] D. Zhang, Z. Fu, and L. Zhang, "An improved TS algorithm for lossminimum reconfiguration in large-scale distribution systems," Electr. 
Power Syst. Res., vol. 77, no. 5-6, pp. 685-694, 2007, doi: 10.1016/j.epsr.2006.06.005.

[30] N. Gupta, A. Swarnkar, K. R. Niazi, and R. C. Bansal, "Multi-objective reconfiguration of distribution systems using adaptive genetic algorithm in fuzzy framework," IET Gener. Transm. Distrib., vol. 4, no. 12, pp. 1288-1298, 2010, doi: 10.1049/iet-gtd.2010.0056.

[31] J. S. Savier and D. Das, "Electrical Power and Energy Systems Loss allocation to consumers before and after reconfiguration of radial distribution networks," Int. J. Electr. Power Energy Syst., vol. 33, no. 3, pp. 540-549, 2011, doi: 10.1016/j.ijepes.2010.11.007.

[32] F. Ding and K. A. Loparo, "Hierarchical Decentralized Network Recon figuration for Smart Distribution Systems - Part II : Applications to Test Systems," IEEE Trans. POWER Syst., vol. 30, no. 2, pp. 744-752, 2015.

[33] J. Zhu, X. Xiong, J. Zhang, G. Shen, Q. Xu, and Y. Xue, "A rule based comprehensive approach for reconfiguration of electrical distribution network," Electr. Power Syst. Res., vol. 79, pp. 311-315, 2009, doi: 10.1016/j.epsr.2008.07.001.

[34] T. Niknam and M. S. Sadeghi, "An Efficient Evolutionary Optimization Algorithm for Multiobjective Distribution Feeder Reconfiguration," Int. J. Control. Autom. Syst., vol. 9, no. 1, pp. 112-117, 2011, doi: 10.1007/s12555-011-0114-6.

[35] T. T. Nguyen and A. V. Truong, "Distribution network reconfiguration for power loss minimization and voltage profile improvement using cuckoo search algorithm," Int. J. Electr. Power Energy Syst., vol. 68, pp. 233-242, 2015, doi: 10.1016/j.ijepes.2014.12.075.

[36] H. Ahmadi and J. R. Martí, "Minimum-loss network reconfiguration: A minimum spanning tree problem," Sustain. Energy, Grids Networks, vol. 1, pp. 1-9, 2015, doi: 10.1016/j.segan.2014.10.001.
Title Arabic:

\section{هيكلة مثالية لشبكات توزيع القدرة باستخدام محسن دوار الشمس لتقليل المفاقيد التمايد}

\section{Abstract Arabic:}

يقدم هذا البحث طريقة هيكلة مثالية لثبكات توزيع القدرة معتمدا علي تقنية

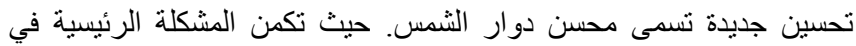

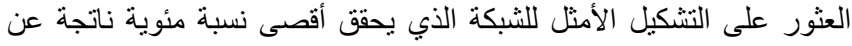

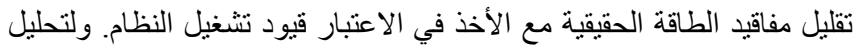

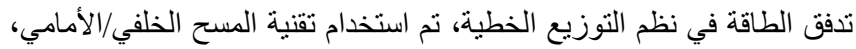

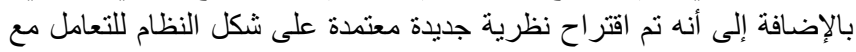

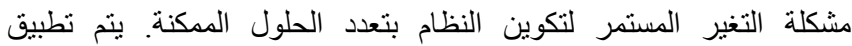

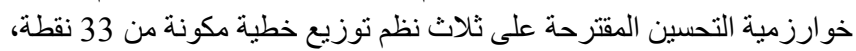

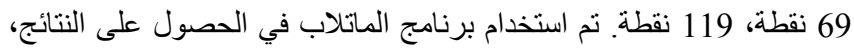

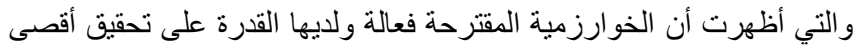
نسبة مئوية لتقليل مفاقيد الطاقة. وللتحقق من كفاءة الطريقة المقدمة أيضا تم مقارنة نتائجها مع نتائج طرق التحسين الأخرى. 